\title{
Hybrid Design for Automotive Body Panels
}

\author{
Andre Camboa
}

MIT-Portugal

\author{
Helena Silva, Alexandre Teixeira and Bernardo Ribeiro \\ CEIIA
}

Joao Nunes

University of Minho

\begin{abstract}
The increasing trend for electric mobility adoption brings new challenges to the automotive industry, requiring a new approach to the manufacture processes, materials adopted and adaptation the market needs. The conventional technologies used to manufacture automotive parts imply significant overhead costs (tooling, assembly, etc.) which can only be justified by large series. The need of light and cost effective materials was the driving force of this study, acknowledging that the growth of the electric vehicles market will be driven by price. The study aims to deliver a hybrid design material solution that would offer quality and security to the vehicle, affordable to everyone, developing engineered solutions in terms of design and production process.
\end{abstract}

To the study were considered exterior body panels that are conventionally manufactured by sheet metal stamping or conventional thermoplastic injection, both having associated high investment costs related with tooling. To follow up this case study was defined as constrains that small series should be considered and weight reduction has to be achieved. The adoption of engineered materials leading to hybrid body panel's configuration was studied with increased resistance and reduced weight, using processes with low cost assembly operations and low tooling investment for a start. Structural reinforcement inserts were used on the test case to provide the desired results on the final component behavior.
The approach taken, considered different materials and methodologies focusing on the use of DCPD RIM components having as baseline the materials used nowadays in the automotive industry for the same type of exterior body panels. For deeper understanding on exterior panels' state of art, an analysis through several vehicle doors was made, analyzing the materials used and their combination. As a result, different combinations of materials were considered as adequate for weight reduction and for production on small production series.

Virtual simulation of two exterior body panels' solutions was done demonstrating the potential of DCPD as a hybrid solution to deliver structural consistence in conjunction with weigh reduction at a reduced cost.

\section{INTRODUCTION}

The transportation paradigm is suffering changes specially driven by the increasing price of crude and the need to decrease $\mathrm{CO}_{2}$ emissions. The development of vehicles capable of using alternative energy sources with relatively competitive energy efficiency and reduced environmental impact is the strategy followed by a significant number of automotive manufacturers. Economy forecast and, in parallel, further scientific studies have been showing that the most promising solution for the next few decades is the adoption of the electric mobility $[\underline{1}, \underline{2}]$. Electric mobility besides having lower operational cost considering that electric powertrains 
are more efficient should also offer zero $\mathrm{CO}_{2}$ tailpipe emissions.

Although electric energy has been already used as propulsion in some vehicles, its massive introduction in automotive sector is still an enormous challenge. Electric vehicles use is limited to low range distances due to its batteries low energy storage capacity, requiring technological advances in batteries and whole vehicle weight reduction to improve vehicle efficiency and energy consumption. The adoption of electric vehicles is expected to be slow compromising the amount of vehicles to be manufactured in the near future. Vehicles shall be produced in small to medium series constraining the selection of materials type and cost, manufacturing processes and components configuration. Contrary to high production volume industries where cars are manufactured by processes that require large initial tooling investment, it is estimated that electric vehicles will need to use other solutions to achieve the market by a competitive price.

Steel is conventionally used as the main material for exterior body panels providing good strength and stiffness properties with very small thicknesses. Some projects, such as the UltraLight Steel Auto Body (ULSAB) []ㅡ are still developing design optimization methods for automotive body steel structures studying concepts as hollow resistance and its reliability. Although its good capacities, steel has high density comparing to other materials having the triple of aluminum ( $\mathrm{Al})$ and the quintuple of magnesium $(\mathrm{Mg})$.

Aluminum body panels combine low density, high strength and excellent corrosion resistance, becoming a good choice for automotive industry [4], even if presenting some welding limitations. However, steel and aluminum entail significant costs being both related to conventional stamping technologies which require high investment in equipment and tooling, suitable for large production volumes []ㅡ. Ultra-light magnesium alloys presents some disadvantages such as poor creep resistance at temperatures above $100^{\circ} \mathrm{C}$ as well as worst corrosion resistance, being more expensive with higher manufacturing associated costs, despite its ultra-low weight [6].

Carbon based composites are the first choice for first class applications, where the cost is covered by the extreme need of light weighted and stiff solutions. Glass fibre (GF) reinforced composites shown to be very good solutions in terms of strength, corrosion resistance and impact behaviour. However these materials are employed to manufacture external body panels as rear body panels in many commercial vehicles through the use of sheet moulding compounds (SMC), processed by heated compression moulding. These SMC parts, in spite of the benefits they have, may only be used for large production series of vehicles, presenting some recycling and repairing limitations, higher cost than those in steel. For small/medium automotive production volumes, hand lay-up labour intensive techniques are usually employed to manufacture GF based composites. These manufacture processes have also some constraints as high manpower skills and respective cost. Resin Transfer Moulding (RTM) process is starting to be a recurrent option to reduce hand labour, increase quality of the final product, reduce cost when high cadence is required, to achieve repeatability on the process and also to monitor the process variables like the pressure applied. Alternatively expensive carbon fibre (CF) reinforced composites tend to be applied when high stiffness/weight ratios are required in advanced applications, e.g. structural parts for sport car chassis or monocoque bodies. The production rate of such parts is usually small and the requirements high. The technologies used as manufacturing methods are heated compression moulding and autoclave based. Carbon fibre based composites are very promising and attractive materials for automotive application since its strength/weight and stiffness/weight ratios are very attractive. With the increasing need and maturity of the carbon reinforced composites market, the costs should decrease and therefore will tend to be largely used in the near future.

Polymeric parts, besides their lightweight characteristics, can save thirty times more energy during automobile overall life cycle than the energy that was used during manufacturing of such parts [7]. Considering dicyclopentadiene (DCPD) it is possible to achieve lightweight low-cost configurations. Dicyclopentadiene was first used on the manufacturing of trucks and agricultural vehicles exterior components but, due to its low density, begun to be also applied in vehicles external panels. Such panels processed by reaction injection molding (RIM) consist in a thermosetting catalytic mixture of DCPD monomers mixed together under pressure and injected into closed mold, where the final cure reaction (cross linking polymerization) takes place. This material ensures adequate exterior surface quality, lightness and a great economic potential for production series starting from 500 units [ $\underline{8}$ ]. However, due to its lower mechanical properties when compared with metal components usually requires the application of sub-structures or metallic stiffening reinforcements to avoid undesired deformations, what can result in applied loads and/or thermal expansion generated by the exposure to high environmental temperatures.

The adoption of lightweight solutions and materials decreases final weights of components considering the same part geometry [6]. By reducing the overall weight of the vehicle parts it is possible to reduce energy consumption on electric vehicles, enlarging travelling range distances and reducing the overall environmental impact of the vehicle. To reduce weight and costs several modifications shall be made in a vehicle, from the structural design, passing by the use of advanced materials technologies and finalizing on an intelligent and engineered choice on the manufacturing 
processes [9]. It is not cost effective to produce low production volume vehicles using conventional materials and technologies since the initial tooling and manufacturing investment will be hardly amortized. Thus, employing low cost technologies and new material solutions will allow the production of automotive components on small series with low weight complying with the same performance criteria.

With the objective of developing new design configurations for exterior body panels a survey was carried out to assess lightweight automotive exterior panels by using as first approach vehicle doors due to its lower analysis complexity in terms of structural requirements in comparison to other structural automotive components [10]. The aim is to understand what can be achieved using DCPD based configurations in the automotive exterior panels. It was also carried a 3D concept study of an automotive exterior body panel taking into account its materials, final weight and structural behavior to explore lightweight configurations and manufacturing processes of the most lighter solution. Still, on the manufacturing point of view, it was discussed its potential for low production volumes. By the end, the study carried on also considers the environmental impact of that lightweight solution.

\section{BODY PANELS DESIGN SURVEY}

A survey was carried out to find the relationship between the used materials and its geometry with special focus on DCPD configurations. This survey, based on a Lotus benchmarking study [10], was driven to look for opportunities to reduce weight in vehicle systems, sub-systems and components. In addition, other four doors were disassembled and analyzed to better support the survey study. The benchmarking study allowed a more coherent analysis on the current state of art of the materials applied (see Table 1), standard door areas (see Figure 1) and their respective weight (see Figure 2). The correlation between automotive doors materials and its weight was taken from the Lotus Engineering benchmark [10] that calculates door areas by its overall width and height, discounting the curvatures of its A and B pillars. Figure 1 shows overall door dimensions that will support this design study, presenting a large range of doors dimensions from vehicles such as Toyota Venza, Audi A2, Mercedes S Class, Peugeot 206, Volkswagen Golf, Suzuki Ignis (Lotus Benchmarking) [1ㅜ] , Ford Focus, Fiat Panda, Aixam 400 and Ebil Norge Buddy 09. The latest four representative automotive doors were added to those on Lotus benchmarking to enrich the study towards a bigger spectrum. Among the former four vehicles, one is an electric vehicle and the other three use conventional internal combustion engines platforms being converted in to battery electric vehicles.
Table 1. Configuration of the doors.

\begin{tabular}{r|l}
\hline Vehicle & Door configuration \\
\hline Ford Focus & Steel side door \\
Toyota Venza & Steel side door \\
Suzuki Ignis & Steel side door \\
Audi A2 & Aluminum door \\
Peugeot 206 & Steel side door \\
Volkawagen Golf & Steel side door \\
Ebil Norge & DCPD panels plus steel frame \\
Mercedes S Class & Aluminum side door \\
Aixam 400 & Polymer panel plus steel frame \\
\hline
\end{tabular}

Figure 1 shows the main dimensions of the doors used on the ten cars under analysis and figure 2 presents the areas of each car side door calculated using its overall width and height. As can be seen on figure 2 the whole steel door used by Ford Focus presents the highest area, followed by Mercedes $\mathrm{S}$ Class equipped with an fully aluminum door (see Table 1). To better distinguish the materials in figure 2 , the different materials are represented with different colours/patterns. It is easily concluded that the recurrent material used in automotive industry is still the steel, being hardly followed by aluminium alloys.

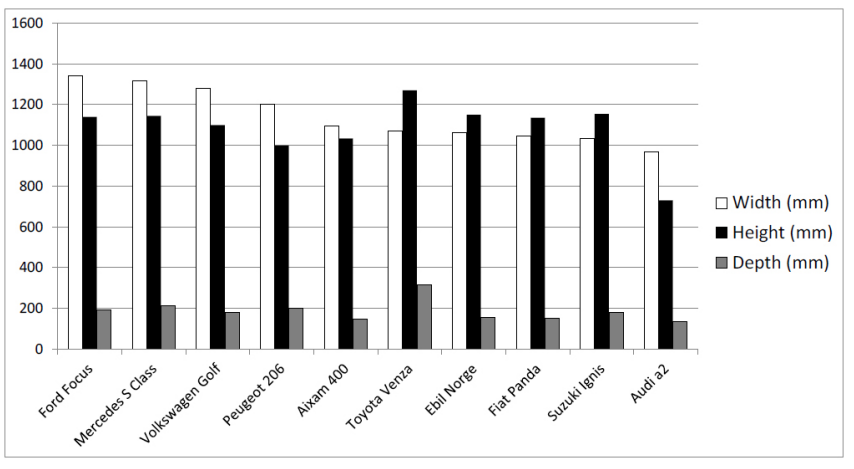

Figure 1. Dimensions of the doors studied.

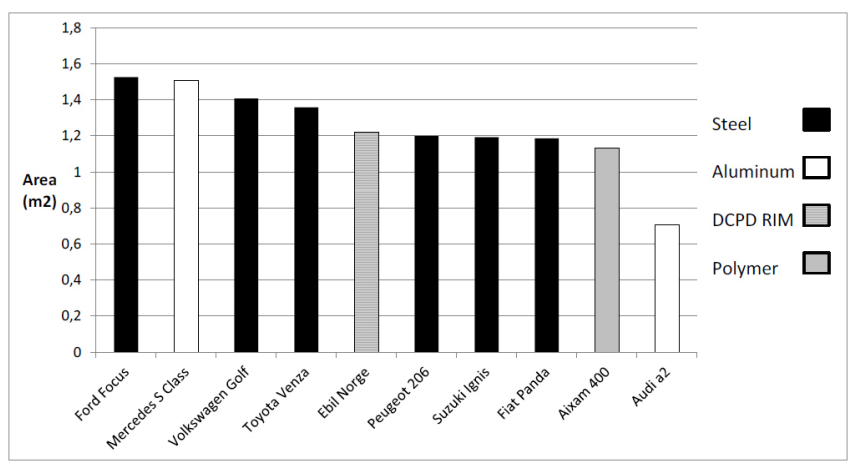

Figure 2. Area of the doors considering the values from Lotus benchmarking study. 
In figure 3 it is analyzed and compared the door weight where Ford Focus has the heaviest door panel that is followed by Toyota Venza, both having whole door steel panels. Aixam 400 and Audi A2 have the lightest panel values followed by Mercedes S Class and Ebil Norge Buddy09. It should be highlighted that Aixam 400 has a side door (see Table 1), composed by a steel frame and a polymer outer skin and Audi A2, a solid aluminum door. Subsequent values are driven by an entire Mercedes S Class aluminum door and the one presented by Ebil Norge Buddy 09 composed by DCPD and steel. The side door of this car is composed by three DCPD panels external, internal and a structural panel - and one structural steel panel placed between the previous. Such engineered solutions are used intelligently to save weight without compromising the quality, even if requiring the use of three different moulds for each door, giving a total of six moulds (left-hand and right-hand) for the whole car.

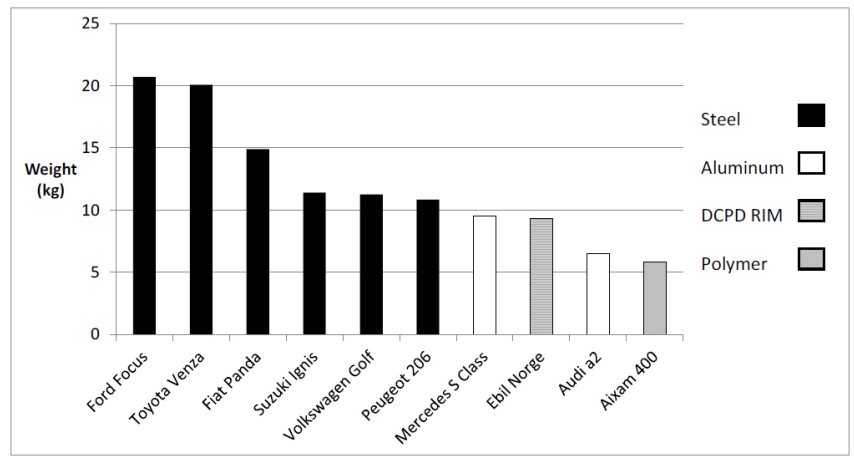

Figure 3. Door weight considering the values from Lotus benchmarking study.

To better analyze the relationship between the calculated areas and measured weight, a ratio between weight and area was calculated. On Figure 4, the calculated weight/area ratio leads to an immediate and easy understanding that the most promising lightweight external door panels are those based on two or more materials system or entire aluminum solutions. Comparing weight/area ratios, is shown that the best compromise is achieved with steel reinforced designs, whether the worst results were obtained on components entirely made in steel (Ford Focus).

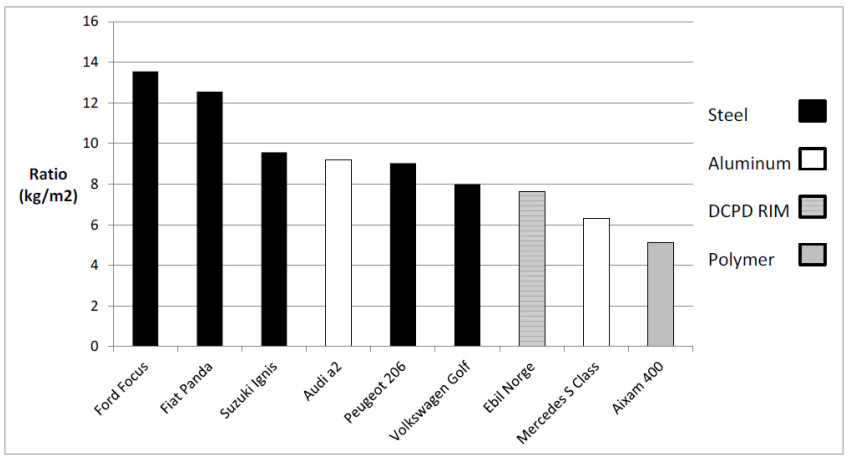

Figure 4. Ratio between weight and area of each door.

In order to visualize the mass reduction achieved, the heaviest door area was considered as the referential to the other doors and the mass saving was calculated to each door. Thus, all vehicle side doors were normalized to the Ford Focus door area by dividing the Ford Focus area to each vehicle door area. This factor was then multiplied by each vehicle door weight obtaining the adjusted mass of each door. The adjusted mass and mass saving equations used are presented below:

$$
\text { Adjusted mass: }\left(\frac{\text { Focus width } \times \text { Focus height }}{x \text { width } \times x \text { height }}\right) \times x \text { weight }
$$

Mass saved: Focus weight-adjusted mass

Adjusted mass values for each vehicle side door represents the weight that the door might have with the same door area of Ford Focus using the same design principles and materials. Thus, as Figure 5 shows, it is possible to compare directly all vehicles side door weight savings. Aixam 400 side door presents an adjusted mass of $8 \mathrm{Kg}$ (see Fig. 5) and a weight saving of approximately $12 \mathrm{~kg}$. The materials and the construction of this door represents the highest potential for weight saving. On the contrary, Toyota Venza side door shows to have a $2 \mathrm{Kg}$ penalty presenting a door similar size of Ford Focus representing the less favorable door design to be used for weight reduction.

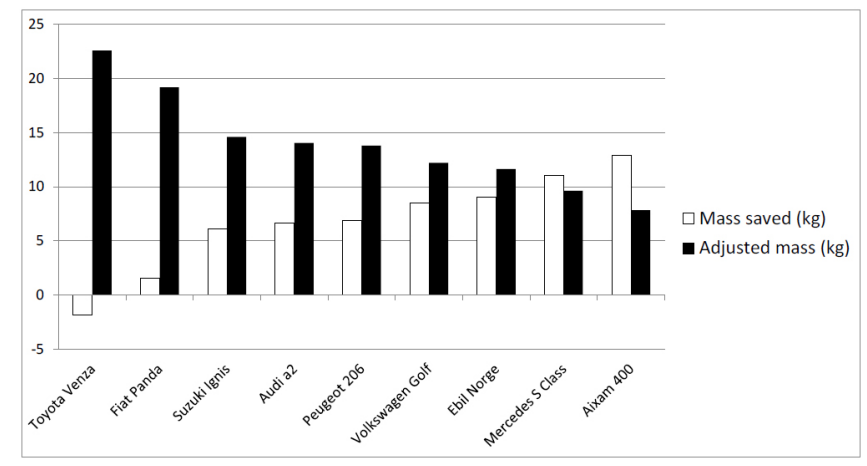

Figure 5. Adjusted weight and mass saved compared to the heaviest door (Ford focus). 
From the analysis made, it was possible to conclude that doors using a combination of materials or aluminum solutions presented the lowest weights. Taking into account the doors size, those doors entirely manufactured in steel (e.g. Ford Focus and Toyota Venza) are the heaviest, while the aluminum door of Mercedes S Class, almost with the same size, presents approximately half of the weight. The two smallest side doors - Aixam 400 and Audi A2 - even presenting real closer weight value (Figure 3) are far from having similar characteristics as it is shown in Figures 4 and $\underline{5}$, in terms of weight/area ratio and adjusted mass saving, respectively. Considering Ebil Norge Buddy 09 body panels configuration, the values closer to the aluminum were achieved using steel reinforced with DCPD. In order to better understand the potential of using DCPD based exterior body panels a design study was carried out from the comparison variables of area and shape.

\section{A DOOR PANEL DESIGN STUDY}

The previous analysis pointed that the combination of materials as well as the use of aluminum would lead to light door solutions. Although decreasing weight became one of the most important requirements of automotive industry, it is also required that adequate mechanical properties are kept constant. In order to accomplish this automotive door analysis, the structural behavior and performance of external door panels made in different materials was compared using finite element methods (FEM). A study of different solutions using the aluminum and DCPD as door panel materials was done to approach the displacements caused by fixed forces. On the simulation study only the exterior panel and its reinforcement beam were considered, being required for further and more valid result, a complete test including the entire car with the entire door assembled.

This preliminary test is intended to understand what results can be achieved when a combination of different materials is considered. These figures have, as value of reference, the mechanical behavior and the weight of a $1 \mathrm{~mm}$ thickness steel panel without any reinforcement subjected to a load of $10 \mathrm{~N}$ distributed over a circular area with $100 \mathrm{~mm}$ diameter as can be seen in the Figure 6 . Then, the same panel geometry was used on all carried tests adopting different properties.

Therefore, the structural performance of the steel sheet panel was defined as baseline when comparing with lighter materials with beams reinforcement to improve its behavior. As a first approach were considered steel beam reinforced aluminum and steel beam reinforced DCPD door panels. To compare the final results, total weights, including reinforcement beams, were calculated to determine the best compromise between performance and total weight. The aim of this part of the study was to show the possibility of achieving the same structural performance of steel by combining lighter materials. Abaqus finite element analysis
(FEA) software was used at this stage only on the elastic regime [11] and the values of Table 2 were adopted [12]. The loaded area and rigid fixing points were defined as presented on Figure 6. The load was applied perpendicularly to the external panel surface and fixing supports considered on the right and left door extremities (hinge and lock sides).

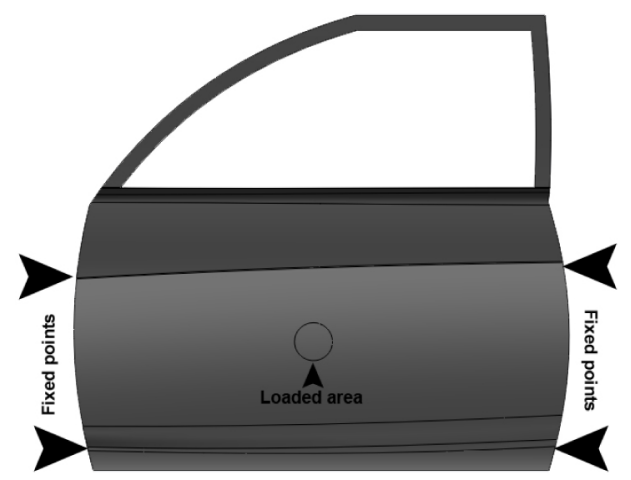

Figure 6. Loading and fixing zones

Table 2. Material properties

\begin{tabular}{r|ccc}
\hline & $\begin{array}{c}\text { Density } \\
\mathbf{\rho} \\
\left(\mathbf{M g} / \mathbf{m}^{3}\right)\end{array}$ & $\begin{array}{c}\text { Tensile modulus } \\
\mathbf{E} \\
(\mathbf{G P a})\end{array}$ & $\begin{array}{c}\text { Poisson } \\
\text { Ratio }\end{array}$ \\
\hline Steel & 7.85 & 210 & 0.3 \\
Al & 2.8 & 70 & 0.36 \\
DCPD & 1.03 & 2 & 0.39 \\
\hline
\end{tabular}

For the overall simulation the designed external door panel had its thickness varied from $1 \mathrm{~mm}$ to $5 \mathrm{~mm}$. This procedure was taken to Aluminum panel and DCPD panel totalizing 10 configurations, 5 DCPD and Aluminum based panels with thicknesses from $1 \mathrm{~mm}$ to $5 \mathrm{~mm}$.

Materials with lower mechanical properties require more investment on reinforcement in order to achieve acceptable performance. Thus, a steel reinforcement beam was then designed for the aluminum panel acquiring a rectangular section of $20 \times 40 \mathrm{~mm}$. This reinforcement was assembled in a diagonal direction crossing the loaded area (igure 7).

The DCPD door panel was analyzed and, having lower mechanical properties than aluminum, some strategic increments of thickness were done in order to respond better to the load. The reinforcement beam was increased from rectangular section of $40 \times 20 \mathrm{~mm}$ to a rectangular section of $80 \times 20 \mathrm{~mm}$. This reinforcement had its thickness varied from $1 \mathrm{~mm}$ to $5 \mathrm{~mm}$, as well as the for aluminum panel. The reinforcement was positioned crossing the loaded area (Figure 8). All the assembled configurations totalized a matrix of $5 \times 5$, with 25 different configurations for each aluminum and DCPD panels. 


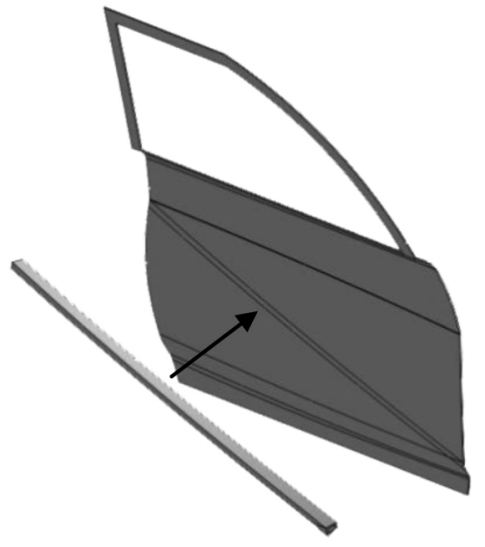

Figure 7. Steel reinforcement beam for aluminum panel

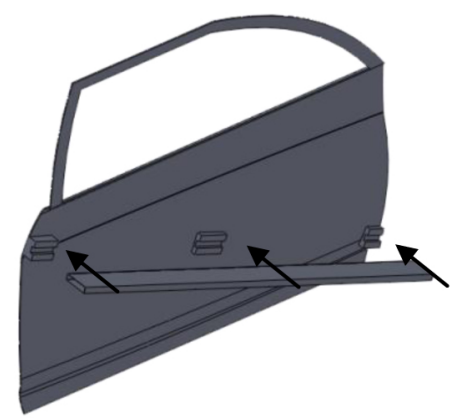

Figure 8. Optimized steel reinforced DCPD panel

The first trial with $1 \mathrm{~mm}$ thickness steel panel without any reinforcement was simulated. This panel presented a total weight of $8.24 \mathrm{~kg}$ and $8,68 \times 10^{-03} \mathrm{~mm}$ of mid-span displacement with the above mention load (see Figure 9). These figures were kept as baseline and a ratio was calculated between its displacement and weight. These values were compared with the following 50 configurations of steel reinforced aluminum panel and steel reinforced DCPD panel.

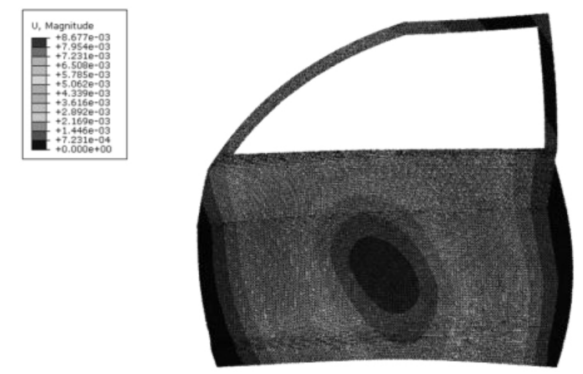

Figure 9. Steel sheet panel displacement

For the Aluminum panel the displacement results, when compared to the single steel panel, have shown an improvement, as can be seen in the figure 10. All displacement's figures remained below of the steel panel. But in terms of total weight, only a range of 6 values varying from $4.17 \mathrm{~kg}$ to $7.35 \mathrm{~kg}$ were shown to be acceptable to achieve the study desired weight.

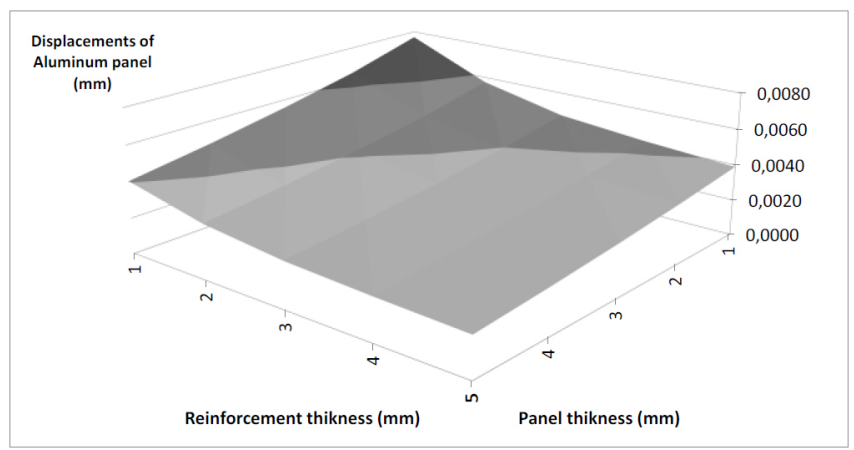

Figure 10. Displacement of steel reinforced Aluminum panel (mm).

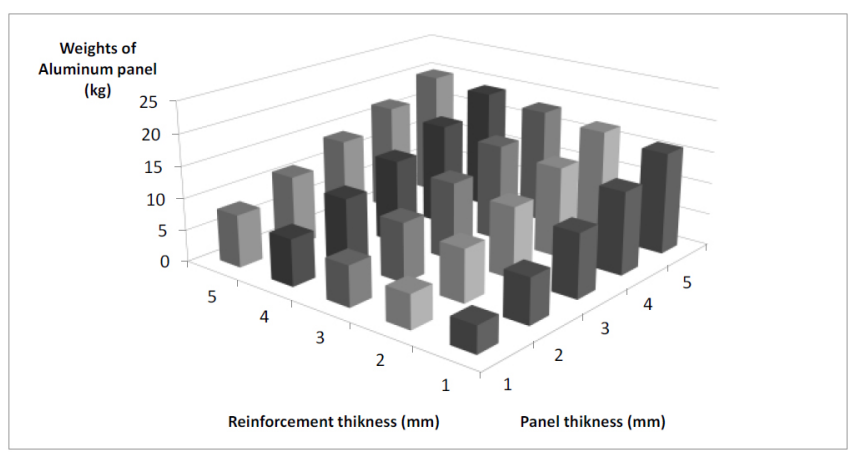

Figure 11. Total weight of steel reinforced aluminum panel (kg).

In terms of ratio between displacement and weight for the aluminum solution (Figure 12), 23 from 25 presented lower values than the single steel panel making them acceptable. Considering the values within the range of acceptable ratios, a configuration with the lowest weight was chosen, a configuration with a $1 \mathrm{~mm}$ thickness aluminum panel reinforced with $3 \mathrm{~mm}$ steel with a total weight of $6.37 \mathrm{~kg}$. This represents a weight saving of $1.87 \mathrm{~kg}$ or $23 \%$ less than the baseline value (steel panel).

The results of DCPD door panel tests were the following, represented on figure 13. In terms of displacement all the results become better than the single steel panel, making them all acceptable. Regarding the total weight of such configuration (Figure 14), a higher range of values, compared to the previous aluminum configuration became acceptable, varying from $3.43 \mathrm{Kg}$ to $7.77 \mathrm{Kg}$. 


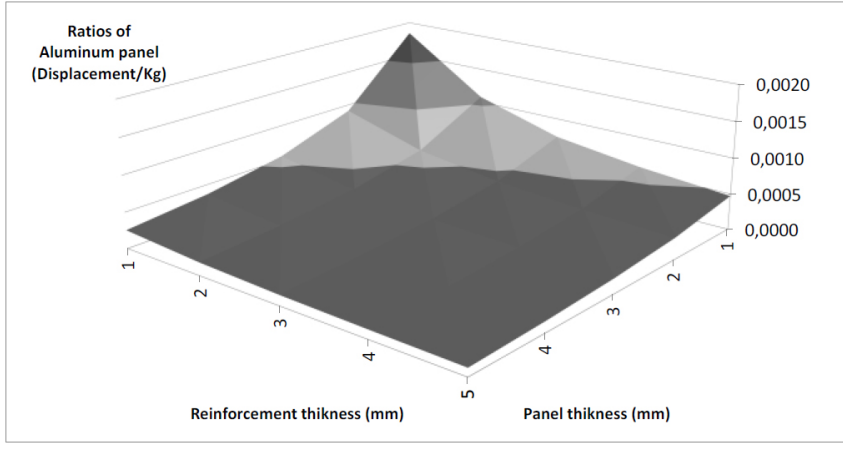

Figure 12. Ratio between displacement and final weight for steel reinforcement Aluminum panel.

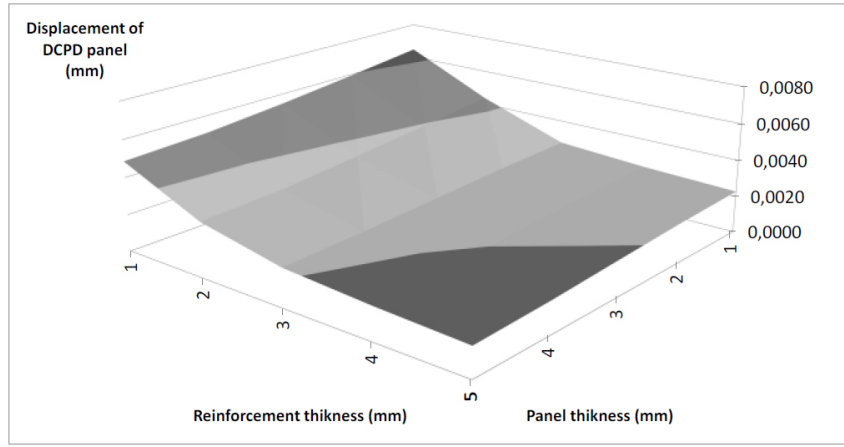

Figure 13. Displacement of optimized steel reinforced DCPD panel (mm).

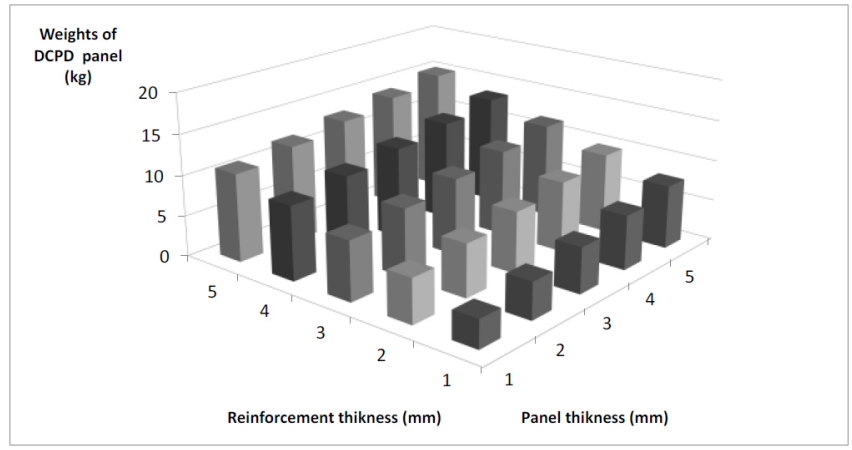

Figure 14. Total weight of optimized steel reinforced DCPD panel (kg).

Considering the ratio between displacement and total weight for this DCPD panel (Figure 15), also 23 from 25 values are acceptable, showing a wide range of values as well as aluminum configuration. Thus, taking into account the lowest value of ratio and the manufacturability of DCPD that only is acceptable from thicknesses higher than $3 \mathrm{~mm}$, a door with the total weight of $5.6 \mathrm{~kg}$ was selected. Comparing to the single steel panel a decrease of weight, of $2.64 \mathrm{~kg}$ or $32 \%$ was achieved.

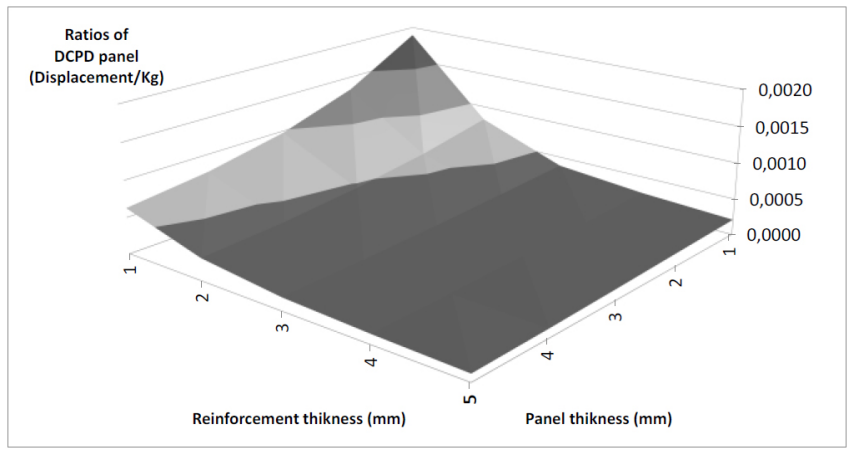

Figure 15. Ratio between displacement and weight for the optimized steel reinforcement DPCPD panel.

Due to little changes on reinforcements, makes DCPD and aluminum panels inappropriate to be compared. However, it is shown that a $12 \%$ weight difference benefits DCPD that shows to have potential to offer lighter solutions when compared with aluminum. Considering their ratios, a subtraction between them was done in order to better understand the major differences between the panels. For this specific case the positive values represents the conditions where the DCPD solution is better and the negative ones where aluminum solution is better. As can be seen in the Figure 16, Aluminum and DCPD have clearly two different conditions where each material may be used. DCPD shows to be clearly better when thick panels are considered, using low thickness reinforcements, while aluminum presented better values with lower panel thickness and higher reinforcements thickness.

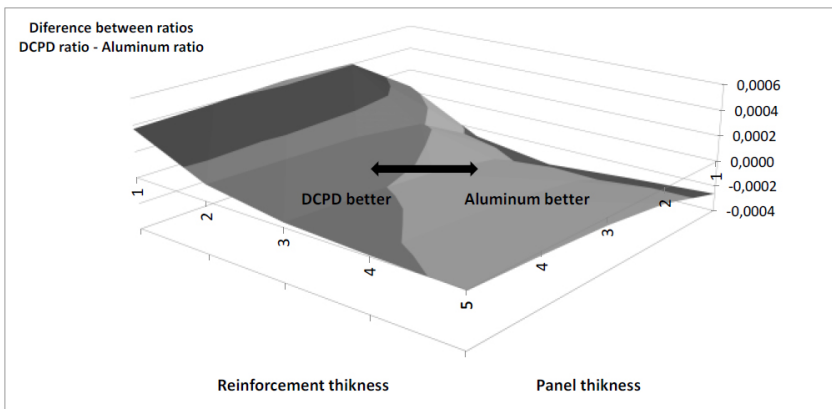

Figure 16. Subtraction of previous ratios, DCPD Aluminum.

Improvements could be more significant when applied to all the exterior body panels of a complete car. The total area of all closures of Toyota Venza mentioned in the Lotus Engineering benchmark study [10] is $17.4 \mathrm{~m}^{2}$, considering that each closure has an outer and inner panel, it can be estimated that a saving of up to $29.4 \mathrm{~kg}$ on the vehicle closures may be achieved when comparing to steel construction. Electric vehicle average energy consumption was estimated to be $0.1 \mathrm{Wh} / \mathrm{km}$ per $\mathrm{kg}$ of vehicle mass [13]; therefore this result may represent an energy consumption 
reduction of $2.9 \mathrm{Wh} / \mathrm{km}$ on the vehicle. This value may become relevant as the complete vehicle body panels are considered.

It can be concluded that, considering similar loading conditions, quite closer results can be obtained on external door panels using different materials, thickness and reinforcements. The adoption of a combination of materials may lead to a more weight effective door panel solution presenting also very similar structural performance to the one obtained with steel, which may be considered a conventional method of exterior auto body panels construction.

\section{MANUFACTURING}

The adoption of body panels using different materials may lead to the need for the manufacture of additional components such as the reinforcement parts. Besides that, the assembly itself may need extra hand labor which can be translated into more investment to the whole production process. Thus, in order to achieve the best weight compromise and best cost effective solution for exterior automotive body panels to be manufactured on low production volumes, additional concerns should be considered such as the manufacturing and assembly process.

From a conventional perspective, steel has been highly used on both structural and exterior body panel's vehicles. In what concerns to exterior steel body panels the manufacturing process mainly used is stamping which, as it has been mentioned before, requires extremely high investment in tooling and equipment. On the other hand, aluminum presents the ideal engineering solution, presenting a third of steel density and satisfying both stiffness and torsion requirements but, again, aluminum processability has higher costs compared to the equivalent steel, result of higher die development costs to compensate its springback behavior- it requires development and application of special coatings and lubricants for dies and presents slower stamping rates to prevent tears and damage. In terms of design, aluminum panels cannot have sharp flanges for joining the inner and outer panels because it tends to split if stamping angles are too sharp. Thus, the additional tooling costs of stamping aluminum make it less favorable [14].

Contrary to steel and aluminum, DCPD due to reaction injection moulding technology, presents a suitable economical batch size [ $\underline{8}]$ for electric and non-electric vehicles produced in small series. Due to its processing pressures and temperatures it is possible to support DCPD components manufacture with lower tools and equipment investment. Also, DCPD processability it is of reduced energy consumption while it becomes able to acquire any geometry without further manufacturing/assembly steps as aluminum and steel. DCPD also presents lower density when compared to both aluminum and steel as could be seen in the
Table 2. DCPD panels may be used with several thicknesses on one same component and, once the chemical reaction that takes place in the mould does not lead to a significant material contraction making it suitable for its geometrical stability. This characteristic may be used to produce DCPD components with inserts of other materials resulting on a finished module, thus saving additional assembling operations. An example of such module is demonstrated in the Figure 17, which refers to the steel reinforced DCPD panel used in the last chapter Door Panel Design Study.

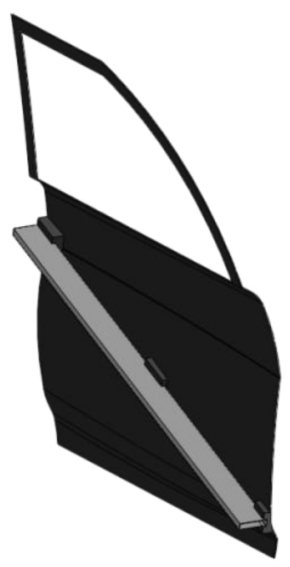

Figure 17. Optimized steel reinforced DCPD panel

An increment of material was used to create a holding zone in order to make possible the application of planar beam reinforcement to the door. Such method can be used in both doors in such way that the same beam or structures can be applied on left and right hand doors. This solution may improve the manufacturing process of the doors, reduce the number of different parts and, it could lead to an overall assembly operations reduction. It should be remembered that the use of this type of solutions is much more complex with metallic components where additional welding is required increasing the final cost and complexity of the components.

The expected manufacturing steps were designed in a flowchart process - figures 18 and 19 - for the steel reinforced aluminum and steel reinforced DCPD panels.

As can be seen in the Figure 18 it is necessary, at least, five main steps to produce the aluminum panel plus the reinforcement. For the steel reinforce are required cutting and forming steps, while, for the aluminum panel is necessary a stamping process in order to give him the desire shape. Both steel reinforcement and aluminum panel are assembled and painted. 


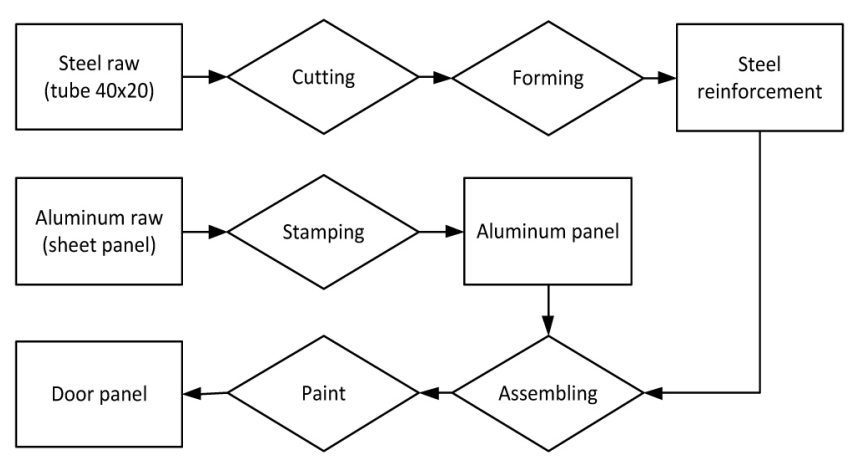

Figure 18. Example for the steel reinforced aluminum panel manufacturing

Regarding to the DCPD configuration, only four manufacturing steps are required (Figure 19).

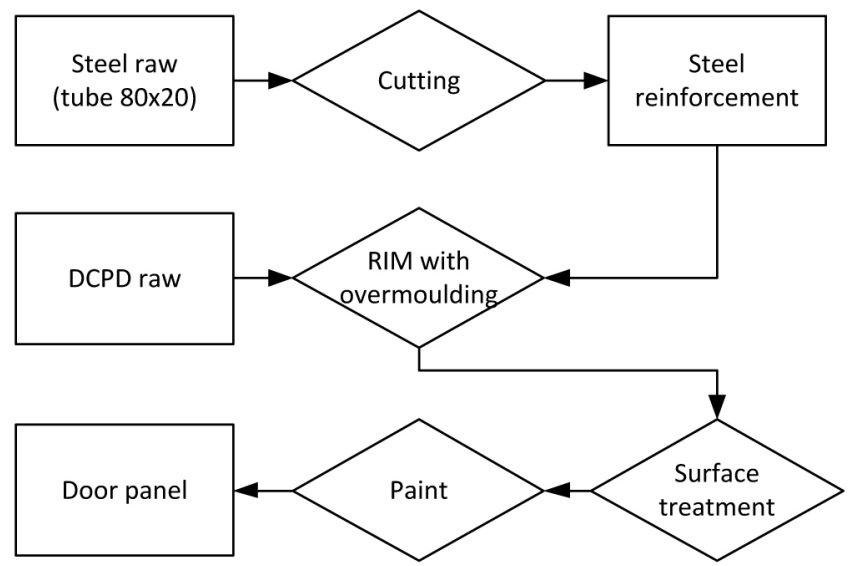

Figure 19. Example for the DCPD reinforced aluminum panel manufacturing

Contrary to the reinforcement for aluminum panel, the reinforcement for DCPD panel just requires cutting since it has designed to be planar. Such design can be achieved with incremental thicknesses in the DCPD panel. As DCPD RIM allows over-moulding the assembly step is not required as for the aluminum door panel since the final panel is already built. However DCPD panels require surface treatment which is mostly hand labour driven. Aluminum requires bigger investment on tooling than steel and steel itself is just worthy for tens of thousands of production units, where reinforced DCPD becomes appropriated for small production volumes, because moulds are cheaper as the process of injection is made at low pressure.

\section{ENVIRONMENTAL IMPACTS}

Recyclability of the automotive components is now a requirement to be taken into account due to the limitation on earth resources and the obligation to manage waste disposal [15]. The need to decrease the $\mathrm{CO}_{2}$ emissions are one of subjects mostly spoken nowadays being now an issue since the planet climate has proven to be changing. Energy consumption from the manufacture process until the vehicle usage is also imperative to be analyzed relatively to its environmental impact. Materials systems used and materials life-cycle should be considered in order to design a sustainable solution in harmony with the environment requirements.

Steel and aluminum based components can be recycled and perhaps re-used, though the processability of the range of alloys or each element imply the use of high energy input to melt the alloy, being constrained by processability by alloy and high $\mathrm{CO}_{2}$ emissions level. Despite the fact that to produce virgin aluminum generates more carbon dioxide emissions than producing virgin steel, reprocessing steel alloys produces almost four times more $\mathrm{CO}_{2}$ than aluminum [16]. In fact these values are highly related to the melting temperature of each material, and to achieve such temperatures, high energy consumption has to be considered.

Regarding to the energy usage, it is estimated that DCPD will present lower values than those last mentioned materials, only demanding $25 \mathrm{MJ}$ of energy for processing one kilogram of material [ $[8]$. Some thermosetting DCPD formulations are not recyclable as the previous metallic alloys since cannot be re-melted and shaped as thermoplastics. However, there are several ways of treating thermosets such as mechanical and thermal recycling (incineration) [15, 17]. Incineration of DCPD should be highly taken into consideration since DCPD is highly exothermal releasing a great amount of heat energy that can be around $41 \mathrm{~kJ} / \mathrm{kg}$. Also, DCPD good processability and resultant reactions is known to contribute to a low emission level, which reduces its environmental impact on its cycle [18].

\section{CONCLUSIONS}

To introduce and stabilize the presence of electric vehicles on the market it is necessary to search and develop competitive solutions, adaptable to low volume manufacturing rates. These solutions shall focus on weight reduction material solutions at a low cost material, manufacture process and assembly, always having as background the use of environmental friendly materials. Quality and reliability will be always considered to design any engineered solution, where safety must be assured. Automotive engineering must extend the use of different materials in order to find optimal weight and cost saving solutions.

An analysis of several doors from different vehicles with different material constitution and design was carried out. All doors were compared on a normalized basis and it could be concluded that it is possible to achieve a weight reduction combining different materials with lower densities. 
A second analysis was done using different materials, namely steel, aluminum and DCPD, on a same geometry exterior body panel and compared by its finite element analysis behavior, manufacturing characteristics and environmental impact. In terms of performance, the adoption of a DCPD solution has shown to give low-weight results maintaining the performance of steel and aluminum body panels. Considering the need of extra reinforcements to sustain its limited strength characteristics (when compared with metallic structures) it shows to be a lighter solution comparing with equivalent parts manufactured with different materials such as steel and aluminum. The implementation of the solution presented in this paper should be further tested and optimized relatively to the materials mechanical properties and specifications required by each body panel location. Further work must be carried out to study the whole door using the materials mentioned in this paper and test it in different mechanical conditions, including when assembled in a conventional car, and better estimating associated manufacturing, energy saving and maintenance costs.

In terms of manufacturing, DCPD shows to be a solution to be used on small production volumes of automotive body panels due to its lower investment in tooling and equipment.

From the recycling perspective, DCPD is far from presenting the same behavior of aluminum and steel, however it presents lower energy usage and $\mathrm{CO}_{2}$ emissions per processed kilogram compared to those, while, in its end of life, it can be incinerated, providing a substantial energy recover due to its chemical energy content.

\section{REFERENCES}

1. SHINNAR, R. "THE HYDROGEN ECONOMY, FUEL CELLS, AND ELECTRIC CARS". Technology in Society, Vol. 25; 2003.

2. BECKER, T.; "ELECTRIC VEHICLES IN THE UNITED STATES A NEW MODEL WITH FORECASTS TO 2030". Center for Entrepreneurship and Technology (CET); University of California, Berkeley; Vol. 1; July 2009.

3. http://www.autosteel.org/en/Programs/ULSAB.aspx

4. "ALUMINUM FOR AUTOMOTIVE BODY SHEET PANELS" The Aluminum Association, Inc.; December 1998. Available on internet site: www.aluminum.org.

5. John, STEIN; Federico, STRASSER; "DESIGN FOR MANUFACTURABILITY HANDBOOK" Chapter 3.2 Metal Stampings; The McGraw-Hill Companies; 2004.

6. KLEINER, M.; GEIGER, M.; KLAUS, A.; "MANUFACTURING OF LIGHTWEIGHT COMPONENTS BY METAL FORMING".

7. MCAULEY, J. W.; "GLOBAL SUSTAINABILITY AND KEY NEEDS IN FUTURE AUTOMOTIVE DESIGN". Environmental Science \& Technology; Vol. 7; 2003.
8. "TELENE, AN ADVANCED FEAUTURE FOR TOMORROW'S DESIGNERS" Telene brochure available on the internet site : http://www.telene.com/downloads.php

9. BROWN, M. D. "LIGHTWEIGHT ELECTRIC/HYBRID VEHICLE DESIGN" Proceedings of the Institution of Mechanical Engineers, Part D: Journal of Automobile Engineering; Vol. 215; 2001.

10. COUNCIL, T. I., \& MARCH, C. T.; "AN ASSESSMENT OF MASS REDUCTION OPPORTUNITIES FOR A 2017 - 2020 MODEL YEAR VEHICLE PROGRAM" Lotus Engineering Inc; The International Council on Clean Transportation; March 2010.

11. http://www.simulia.com/products/abaqus_cae.html

12. MATWEB material property data; available on internet site: http://www.matweb.com/

13. Ribeiro, B., Brito, F., and Martins, J., "A Survey on Electric/Hybrid Vehicles," SAE Technical Paper 2010-01-0856, 2010, doi:10.4271/2010-01-0856.

14. Anish, KELKAR, Richard, ROTH, and Joel, CLARK; "AUTOMOBILE BODIES: CAN ALUMINUM BE AN ECONOMICAL ALTERNATIVE TO STEEL?” Automotive materials; Economics; JOM; TMS-The Minerals, Metals \& Materials Society

15. PICKERING, S.J.; "RECYCLING TECHNOLOGIES FOR THERMOSET COMPOSITE MATERIALSCURRENT STATUS" Composites; Applied Science and Manufacturing; Elsevier; 2005

16. UNGUREANU, C.A.; DAS, S.; JAWAHIR, I.S.; "LIFECYCLE COST ANALYSIS:ALUMINUM VERSUS STEEL IN PASSENGER CARS" Aluminum alloys for Transportation, Packaging Aerospace, and Other Applications; TMS-The Minerals, Metals \& Materials Society.

17. Economy, J. and Andreopoulos, A. G.; "A NEW CONCEPT FOR RECYCLING OF THERMOSETTING RESINS I: THE CASE OF CROSSLINKABLE COPOLYESTERS" Vol 7; Polymers and Advances Technologies;

18. "HEAT CAPACITY, HEAT OF REACTION \& LOWER CALORIFIC VALUE OF TELENE ${ }^{\circledR}$ NON REINFORCED GRADES" Heat Capacity \& Reaction brochure available on the internet site : http:// www.telene.com/downloads.php

\section{CONTACT INFORMATION}

Author: André Magalhães Sá Camboa $\mathrm{PhD}$ Researcher at MIT Portugal Program

Contact: (+351) 969808832

andrekamboa@gmail.com 


\section{ACKNOWLEDGMENTS}

This work is financed by FEDER Funds, through the Operational Programme for Competitiveness Factors COMPETE under the project 13844.

André Camboa thanks FCT (Fundação para a Ciência e Tecnologia) for PhD scholarship (SFRH / BD / 51119 / 2010) under the scope of the MIT Portugal Program in Engineering Design and Advanced Manufacturing - Leaders for Technical Industries focus area.

The Engineering Meetings Board has approved this paper for publication. It has successfully completed SAE's peer review process under the supervision of the session organizer. This process requires a minimum of three (3) reviews by industry experts.

All rights reserved. No part of this publication may be reproduced, stored in a retrieval system, or transmitted, in any form or by any means, electronic, mechanical, photocopying, recording, or otherwise, without the prior written permission of SAE. ISSN 0148-7191
Positions and opinions advanced in this paper are those of the author(s) and not necessarily those of SAE. The author is solely responsible for the content of the paper.

SAE Customer Service:

Tel: 877-606-7323 (inside USA and Canada)

Tel: 724-776-4970 (outside USA)

Fax: 724-776-0790

Email: CustomerService@sae.org

SAE Web Address: http://www.sae.org

Printed in USA 